\title{
Comparison of Two Types of Diets on Losing Weight and Lipid Profile of Overweight/Obese Middle-Aged Women Under Exercise Condition
}

\author{
Mohammadreza Rezaeipour ${ }^{1,2,}$ \\ ${ }^{1}$ Department of Physical Education and Sport Sciences, University of Sistan and Baluchestan, Zahedan, IR Iran \\ ${ }^{2}$ Department of Sports Medicine, National Medical Academy of Postgraduate Education, Kiev, Ukraine \\ ${ }^{*}$ Corresponding author: Mohammadreza Rezaeipour, Department of Physical Education and Sport Sciences, University of Sistan and Baluchestan, Zahedan. P.O. BOX: 98135-987, IR \\ Iran. Tel: +98-9153414047; +38-0932903270, E-mail: rezaeipour@ped.usb.ac.ir
}

Received: October 24, 2013; Revised: April 17, 2014; Accepted: April 25, 2014

Background: A popular dieting guide for the weight loss is the negative-calorie diet; even so, there is still little knowledge about this method.

Objectives:The present study aimed to determine the effects of negative-calorie diet supplemented with exercise, on the weight loss and lipid profile, and to compare its efficiency with low-calorie diet with exercise among middle-aged overweight women.

Patients and Methods: This was a randomized study (the CONSORT statement) carried out at Ukrainian Center of Sports Medicine (Kiev2012). Participants ( $n=66$ ) included sedentary overweight or obese women (age 45-64 years). They were randomly divided into two groups: negative calorie diet with exercise, and low-calorie diet with exercise. Out of all 66 participants, 60 persons completed the study period (three months). The weight parameters, including change in weight and body composition, and blood sample tests were assessed pre-and post-intervention for all subjects and compared to each other. $\mathrm{P}<0.05$ was considered significant. Statistical analysis was performed using SPSS (version 19.0 for windows).

Results: All parameters changed significantly in both groups. Reduction in total cholesterol $(\mathrm{P}<0.05)$ and LDL-cholesterol $(\mathrm{P}<0.05)$ as well as raising HDL-cholesterol level $(\mathrm{P}<0.002)$ were different between the two groups. Decline of the total cholesterol to HDL-cholesterol ratio was similar in both groups.

Conclusions: It seems that the concept of negative-calorie lacks any validity and application. Contrary to expectation, efficacy of both weight-loss diets was the same.

Keywords: Diet, Exercise; Obesity; Overweight; Weight Loss

\section{Background}

Obesity is associated with an increased prevalence of chronic diseases, including type 2 diabetes, high blood pressure and cardiovascular diseases (CVD) (1). About, $70 \%$ of the middle-aged people have an abnormal weight gain. This population is at high risk for obesity (2). Physical dysfunctions, higher healthcare costs, as well as increased morbidity and mortality are some consequences of the obesity during later adulthood (3). Today, weightloss medications and diets are widely used for weight loss and body fitness.

These diets are associated with various side effects influencing the health of the person (4). Exercise alone without any dietary intervention has low efficacy in weight loss. Previous studies have shown that there is a direct relation between nutrition and body condition (5). Therefore, health experts stress on the low-calorie diet consumption. However, recently negative-calorie diet (NCD) has gained a great deal of research and popular attention.

NCD is among the relatively trendy diets, based on the principle of using foods that create a negative calorific effect leading to appropriate weight loss. The origin of the negative-calorie diets idea is still unclear. This notion was first appeared in the website "www.negativecaloriediet. com" as an 80-page downloadable e-book in 2007. The negative-calorie diet is a kind of very low-fat diet (15\% protein, $75 \%$ carbohydrate, $10 \%$ fat) that has a very high carbohydrate and fiber content (6). It is believed that negative-calorie foods help to lose weight by burning more calories than what has been eaten. For example, for digesting a piece of dessert containing 400 calories, the body needs 150 calories of energy. The remaining 250 calories add to the body fat. However, based on the idea of NCD, eating 100 calories of these foods needs to 150 calories for digestion. Actually, the body should burn 50 extra calories simply by eating the food.

According to the supporters of NCD, this diet will contribute more than other diets to weight loss. In other words, more eating loses more weight. The Low-calorie diet (LCD) (15\% protein, $55 \%$ carbohydrate, $30 \%$ fat) help to lose weight by reducing total calorie intake, but they do not help to burn calories. In general, low-calorie diet is high in carbohydrates and low in fat $(7,8)$. A large part of negative-calorie diet includes low-calorie fruits and vegetables that are high in fiber (9-11). Nowadays, there are 
lots of advertisements about the NCD. Notwithstanding the popularity of NCD idea among dietary plans, there has been no scientific evidence about the efficacy of this diet on weight loss. The study of diet is important in different age groups.

\section{Objectives}

The present study aimed to evaluate the effects of NCD supplemented with exercise on weight loss and compare its efficacy with LCD with exercise. Changes in lipid profile of the subjects, body weight, body mass index (BMI), HDL-cholesterol level and total cholesterol to HDL-cholesterol ratio were assessed pre- and post-intervention to assess the weight-loss trend.

\section{Materials and Methods}

This was a randomized clinical trial (RCT) study. Participants of the study $(n=66)$ were randomly selected among overweight or obese women aged 45-64 years who had attended the Ukrainian Center of Sports Medicine (Kiev) to receive weight loss consulting programs. The research team consisted of two physicians (one sport physician and one resident) and four nurses. Enrollment, classification and assignment of subjects to experiments were done under the supervision of a sports medicine physician. Participants were non-smokers and weightstable ( $\pm 2 \mathrm{~kg}$, for more than one year) with no history of regular exercise in at least three months before the study. They had no history of CVD and other disorders such as diabetes, depression, eating disorders, chronic medications, kidney disease, cancer, food allergies or intolerances to items used in meals. Subjects with abnormality in thyroid or electrocardiograph, any history of anti-obesity medication or weight-loss drugs or dietary supplementations for weight-control were excluded from the study.

Throughout the study, participants should not use any type of alcohol, sugar, honey, sugar substitutes, or any of commercial dressings (high-fat and sugar content). The participants were assessed for vital signs. Their blood pressure was measured after the 10-minute-rest period on a seat from right arm (twice, five-minute interval) with a manual mercury sphygmomanometer. The averaged value was used for further analysis. Those subjects with blood pressures lower than 140/90 $\mathrm{mm} \mathrm{Hg}$ were entered into the experiments. Weight loss assessment parameters included body weight, body mass index (BMI), and blood lipid, which were measured pre- and post-intervention.

Body weight was measured to the nearest $0.1 \mathrm{~kg}$ on a digital scale (Scale-Tronix model 5002, Wheaton, IL, USA). Height was measured to the nearest $0.1 \mathrm{~cm}$ by a wallmounted stadiometer. All physical measurements were performed with light street clothing and no shoes. Body mass index (BMI), as body weight $(\mathrm{kg}) /$ height $\left(\mathrm{m}^{2}\right)$ equal to or higher than $25.0 \mathrm{~kg} / \mathrm{m}^{2}$ was defined as overweight and obesity condition. Blood samples were taken from the antecubital vein. Total cholesterol (TC), triglycerides (TG) and high-density lipoprotein cholesterol (HDL-C) were measured by spectrophotometry at $500 \mathrm{~nm}$ using enzymatic kit (Elitech Diagnostics, Sees, France). Low-density lipoprotein (LDL) and low-density lipoprotein cholesterol (LDL-C) were calculated using the Friedewald formula defined as LDL-C = TC-HDL-C-TG/5 (12). The participants did not eat or drink, except water, for 9-12 hours prior the blood test.

Blood sample assessments for further analyses were as follows: the plasma concentration of TC below 200 $\mathrm{mg} / \mathrm{dL}$, LDL-C below $130 \mathrm{mg} / \mathrm{dL}$, TG below $150 \mathrm{mg} / \mathrm{dL}$, and finally, the plasma HDL-C levels below $40-60 \mathrm{mg} / \mathrm{dL}$. Following initial assessments, the participants were divided randomly into two groups. There were no other restrictions (such as blocking and block size). Study group I (34 participants) received the NCD with exercise (NCD sport). Study group II (32 participants) received the low-calorie diet with exercise (LCD sport). Both groups had $5 \%$ caloric restriction from their maintenance energy requirements and $10 \%$ increase in energy expenditure through structured regular exercise. Table 1 shows daily calorie needs, maintenance calorie requirements, estimated by multiplying basal metabolic rate (BMR) and physical activity level (PAL) of the subject. For a more accurate estimate of BMR in women, Equations 1 and 2 were used for the 31-60 years and more than 60 years participants, respectively. Equation 1.

$$
\text { 'Weight }(\mathrm{kg}) \times 8.7)+829
$$

Equation 2.

$$
(\operatorname{Weight}(\mathrm{kg}) \times 10.5)+596
$$

PAL is the ratio of total daily energy expenditure to BMR. At baseline, for selecting participants with a sedentary lifestyle, the PAL values were determined using a customized self-report questionnaire. The questionnaire consisted of a seven point Likert type scale ranging from "not at all" (1) to "every day" (7). The PAL value was scored into one to seven as follows: not at all, less than once a month, 1-2 times a month, about once a week, 2-3 times a week, 4-5 times a week and every day. The exercise frequency of 1-2 times a month or less was considered as continuously inactive $(13,14)$. During the study, the participants had an active lifestyle (exercise session more than three times a week), and PAL was considered 1.5. To assess weight loss in healthy and effective rate, we considered $15 \%$ reduction (ten percent of energy expenditure and five percent of caloric restriction) in the maintenance calorie needs (15). Participants used a suitable method for identifying their diet and beverage habits. They recorded food and beverage consumption (including water) for four days (three days a week and a weekend day). They did it at the start of the study (baseline) and every month during the study.

They used a diary that was approved based on household 
measures. Diaries were checked for completeness and energy, and macronutrient compositions were calculated using the diets in details software. The NCD include more than 100 different foods containing high level of proteins, vitamins, carbohydrates, dietary fiber and minerals needed for a healthy condition. It consists of lean protein such as poultry, red meat, fish, and eggs, vegetables, and fruits. Fruits consist of apple, blueberry, cranberry, grapefruit, honeydew, lemon/lime, mango, orange, papaya, pineapple, strawberry, tangerine, watermelon. Poultry sources includ chicken and turkey breast. Red meat consist of top round, extra lean sirloin, game meats. Fish sources include all varieties such as buffalo fish, catfish, clams or cooked, cod steaks, crab, crayfish, flounder, mussels, oysters or half shell, shrimp, trout and tuna. Eggs include egg whites and whole eggs in moderate quantities but at least about one yolk a day. Vegetables consist of asparagus, bean sprouts, beetroot, broccoli, cabbage, carrot, cauliflower, celery, cucumber, green beans, kale, leeks, lettuce, radish, spinach, tomato and turnip.

Traditional methods of weight loss include low-calorie diets. Low-calorie foods list, as described above, include low-fiber fruits and vegetables as well as other foods that were not in the NCD foods list. All groups received special recipe developed with food guide pyramid and dietary guidelines (United States Department of Agriculture), The UK Food Standards Agency (FSA), and the NCD plan $(14,15)$. Energy expenditure increased equally in both groups by undergoing supervised exercise, five days a week (two weight-training sessions a week as well as three sessions of aerobic activity). The peak oxygen consumption was $65 \%$ to $85 \%$ (starting the training course at $40 \%$ of peak oxygen consumption). We used heart-rate monitors (Bowflex, Nautilus Inc, Canada), for measurement of exercise-induced heart rates [220-age $\times(65$ to $85 \%)$. In addition, indirect calorimetry (Fitmate, Cosmed, Italy) was used to measure exercise duration necessary to expenditure equal to $10 \%$ of daily calorie needs in each session for everyone. The method did not change during the study. At the start of the experiments, the participants had a weekly meeting. They were instructed to preserve their current PALs and diets throughout the intervention and to report any problems that could affect their involvement in the study. We explained all procedures and requirements to participants. They voluntarily signed a consent form before enrolling in the study. The local ethics committee approved the study protocol.

All statistical data of the study were expressed as mean \pm SD (standard deviation). The normal distribution of the collected data was evaluated using the KolmogorovSmirnov test. The data were normally distributed. The pre- and post-intervention results for the groups were compared using the paired $t$ test, and the differences between the groups were evaluated by the independent $t$ test. The linear regression analysis ( $R$ ) was used to examine a relation between all significant values (dependent) and weight change (independent). Statistical analysis was performed using SPSS (version 19.0 for windows). A P value less than 0.05 were considered as statistically significant.

\section{Results}

The final sample size was 60 women in good health (30 participants in each group). Six participants did not follow their individual PALs or/and diets, thus they were excluded from further assessments. Weight loss and lipid profile change with exercise and diet takes at least 12 weeks. Therefore, the study stopped after three months. The demographical characteristics for individuals who completed the three-month intervention were presented in Table 2. Most participants were white ( 97\%), and the remaining were African ( $n=1)$, and “others" $(n=1)$.

There were no significant differences in the values of body weight, TC, HDL-C and LDL-C, in both groups before the treatment. However, results of the assessments showed significant differences with respect to all parameters between pre- and post-intervention of both groups (Table 3). There were no significant differences in the body weight between the NCD sport $(M=8.1, S D= \pm 0.69)$ and LCD sport $(M=8.2, S D=0.7)$ after intervention $(P>0.05)$. There was significant difference with respect to TC and LDL-C values between groups post-intervention $(\mathrm{p}<0.05)$. Additionally, there were significant differences between HDL-C of the NCD sport $(M=3.46, S D= \pm 1.99)$ and in the LCD sport $(M=9.6, S D= \pm 0.7)(P<0.002)$. Linear regression analysis was implemented to find a relation between all significant values and weight change. The relation of TC, LDL-C and HDL-C with weight change was analyzed that revealed no significant effect (data are not shown).

\begin{tabular}{lccc}
\hline Table 1. & Diets and Daily Energy Intake ${ }^{\mathrm{a}}$ & \\
\hline Group & Type of Diet & BMR $\times$ PAL & $\begin{array}{c}\text { Daily Energy } \\
\text { Intake, kcal }\end{array}$ \\
\hline I (NCD) & Negative-calorie diet & $2305 \pm 1$ & $2188 \pm 98$ \\
II (LCD) & low-calorie diet & $2380 \pm 17$ & $2261 \pm 16$ \\
\hline
\end{tabular}

a Abbreviations: BMR, basal metabolic rate; LCD, low-calorie diet; NCD, negative-calorie diet; PAL, physical activity level.

$\mathrm{b}$ Daily energy intake $=($ BMR $\times$ PAL $)-5 \%$

Table 2. Subjects' Morphological Characteristics in Each Group Before Intervention $(\mathrm{n}=30)$

\begin{tabular}{lcc}
\hline & Group I & Group II \\
\hline Gender & 30 & \\
Female & 0 & 30 \\
\hline Male & & 0 \\
\hline Race & 29 & \\
\hline White & 1 & 1 \\
\hline Non-white & $52 \pm 3.5$ & $55 \pm 5.1$ \\
\hline Age, $\mathbf{y}$ & $172 \pm 6$ & $173 \pm 6.7$ \\
\hline Height, $\mathbf{c m}$ &
\end{tabular}


Table 3. Subjects' Demographic Characteristics in Each Group at Pre-Test and Post-Test Plus the P Value of Comparing Mean within Groups

\begin{tabular}{lcccc}
\hline & \multicolumn{2}{c}{ Group I (NCD) } & \multicolumn{2}{c}{ Group II (LCD) } \\
\cline { 2 - 5 } & Before Treatment & 3 Months & Before Treatment & 3 Months \\
\hline Weight, $\mathbf{~ k g}$ & $84.46 \pm 5.5$ & $76.36 \pm 5.3^{\mathrm{a}}$ & $90.16 \pm 11$ & $81.96 \pm 10.7^{\mathrm{a}}$ \\
BMI, $\mathbf{~ k g / \mathbf { m } ^ { 2 }}$ & $28.65 \pm 2.4$ & $25.9 \pm 2.3$ & $30.16 \pm 3.2$ & $27.31 \pm 3.2$ \\
Total-C, $\mathbf{~ m g / d L}$ & $184 \pm 9.2$ & $152.93 \pm 8.48^{\mathrm{a}}, \mathrm{b}$ & $184.86 \pm 8.1$ & $161.13 \pm 7.15^{\mathrm{a}}$ \\
HDL-C, $\mathbf{~ m g / d L ~}$ & $53.33 \pm 2.98$ & $56.8 \pm 3.89^{\mathrm{a}, \mathrm{b}}$ & $53.4 \pm 2.7$ & $63^{\mathrm{b}} \pm 3.32^{\mathrm{a}}$ \\
LDL-C, $\mathbf{\text { mg/dL }}$ & $113.6 \pm 7.95$ & $92.06 \pm 7.1^{\mathrm{a}}, \mathrm{b}$ & $117.2 \pm 6.69$ & $97.2 \pm 5.14^{\mathrm{a}}$ \\
TC/HDL-C ratio & $3.42 \pm 0.24$ & $2.7 \pm 0.24$ & $3.42 \pm 0.24$ & $2.57 \pm 0.17$ \\
\hline
\end{tabular}

${ }_{\mathrm{a}}^{\mathrm{P}}<0.05$ compare to pre-intervention

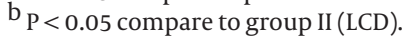

\section{Discussion}

Except for the lack of commitment of some participants to their individual PALs or/and diets who were excluded from the study; we did not face with trial limitations such as potential bias, multiplicity of analyses, and the like, during the study. Reasons for dropping out of the participants were as follows: change in physical activity or/and diet, drinking alcohol, sugar, honey, sugar substitutes, or any of the commercial dressings (high-fat and sugar content) throughout the intervention. Based on the previous studies, weight loss and lipid profile changes due to diet take at least 12 weeks and many investigators have used that fact $(16,17)$. Therefore, the study stopped after 3 months. Blood levels of triglycerides are related to eating, and LCDs reduce its value. Thus, we removed the triglyceride variable from this study.

All parameters, including weight, TC, HDL-C, LDL-C changed in post-intervention compare to pre-intervention in both groups, which showed effectiveness of both treatments. The NCD-induced decrease of TC and LDL-C were significantly greater than the LCD. Both diets were low in fat. Accordingly, it seems that the cholesterol level in each diet has an important influence on the results.

Our findings are consistent with the findings of the Franz et al.'s study evaluating weight-loss efficacy of dietary interventions and exercise, and meal replacements (18). High blood lipids are risk factors for CVD that gets worse with age (19-21). Reduction levels of TC and LDL-C induced by the NCD were not similar with LCD; but effectiveness of both diets was similar with respect to the weight loss. Some other researchers have reported similar results for other diets $(22,23)$. Our data showed that increment of HDL-C levels in NCD sport was significantly lower than LCD sport. HDL-C is the most important determining factor of CVD. Its change is an utmost priority in healthcare because one benchmark to estimate the risk of CVD is the ratio of TC to HDL-C (24-26). As shown in Table 3, the TC/ HDL-C ratio changed in both experimental groups, and there were significant differences in TC/HDL-C ratio between pre- and post-intervention parameters. However, due to the further reduction of TC and also a less increase of HDL-C in NCD compared with LCD, there were no significant differences on TC to HDL-C ratio between the groups in post-intervention. This finding may have clinical applications for weight loss with exercise. Furthermore, results of the simple linear regression confirm our findings that the efficacy of both diets on lipid profile in prediction of cardiovascular disease was the same.

In conclusion, unlike the growing body of advertisements and claims about NCD, both experimental groups (under exercise conditions) showed a similar pattern of weight loss. Weight loss obtained by NCD had no advantage over LCD regarding weight loss and preventing occurrence or development of cardiovascular dysfunctions.

\section{Acknowledgements}

I would like to thank my colleagues in the Faculty and Sports Medicine Centre of Ukraine for their support.

\section{References}

1. Wilborn C, Beckham J, Campbell B, Harvey T, Galbreath M, La Bounty P, et al. Obesity: prevalence, theories, medical consequences, management, and research directions. J Int Soc Sports Nutr. 2005;2:4-31.

2. Ogden CL, Carroll MD, Curtin LR, McDowell MA, Tabak CJ, Flegal KM. Prevalence of overweight and obesity in the United States, 1999-2004. JAMA. 2006;295(13):1549-55.

3. Leigh JP, Hubert HB, Romano PS. Lifestyle risk factors predict healthcare costs in an aging cohort. Am J Prev Med. 2005;29(5):379-87.

4. Hakan E, Bulent O. Some ethical reflections on weight loss diets. Turk J Med Sci. 2011;41(6):951-7.

5. Aslıhan A, Teslime AB, İmge E, Murat VE, Ozgur DID, Murat T. Effects of grape consumption on plasma and erythrocyte antioxidant parameters in elderly subjects. . Turk J Med Sci.2010;40:525-9.

6. Lichtenstein AH, Van Horn L. Very low fat diets. Circulation. 1998;98(9):935-9.

7. Rezaeipour MR, NMAPE PL. Investigating the effects of negative calorie diet compared with low-calorie diet on weight loss and lipid profile in sedentary overweight/obese middle-aged and older people with or without exercise. Specialized doctor in sports medicine. Ukraine: Shupyk, Kiev; 2013.

8. Manore MM. Exercise and the Institute of Medicine recommendations for nutrition. Curr Sports Med Rep. 2005;4(4):193-8.

9. Marion N. Why calories count from science to politics. university of 
california press. USA: Malden Nasheim.; 2012.

10. Duyff RL. American Dietetic Association Complete Food and Nutrition Guide. 4 edHoboken: John Wiley \& Sons; 2012.

11. Soumittra N, Meenakumari B, Parija T, Sridevi V, Nancy KN, Swaminathan R, et al. Molecular genetics analysis of hereditary breast and ovarian cancer patients in India. Hered Cancer Clin Pract. 2009;7(1):13.

12. Allain CC, Poon LS, Chan CS, Richmond W, Fu PC. Enzymatic determination of total serum cholesterol. Clin Chem.1974;20(4):470-5.

13. Chodzko-Zajko WJ, Proctor DN, Fiatarone Singh MA, Minson CT, Nigg CR, Salem GJ, et al. American College of Sports Medicine position stand. Exercise and physical activity for older adults. Med Sci Sports Exerc. 2009;41(7):1510-30.

14. Aarnio M, Winter T, Kujala U, Kaprio J. Associations of health related behaviour, social relationships, and health status with persistent physical activity and inactivity: a study of Finnish adolescent twins. BrJ Sports Med. 2002;36(5):360-4.

15. Bean A. Food for Fitness. 3 edLondon: A\&C Black Publishers Ltd;2007.

16. Noakes M, Clifton PM. Changes in plasma lipids and other cardiovascular risk factors during 3 energy-restricted diets differing in total fat and fatty acid composition. Am J Clin Nutr. 2000;71(3):706-12.

17. Flynn MM, Zmuda JM, Milosavljevic D, Caldwell MJ, Herbert PN Lipoprotein response to a National Cholesterol Education Program step II diet with and without energy restriction. Metabolism. 1999;48(7):822-6.

18. Franz MJ, VanWormer JJ, Crain AL, Boucher JL, Histon T, Caplan W, et al. Weight-loss outcomes: a systematic review and meta-analysis of weight-loss clinical trials with a minimum 1-year follow-up. J Am Diet Assoc. 2007;107(10):1755-67.

19. Grundy SM, Clark LT, Cooper RS, Denke MA, Howard WJ, Hunninghake DB, et al. The Third Report of the National Cholesterol Edu- cation Program (NCEP) Expert Panel on Detection, Evaluation and Treatment of High Blood Cholesterol in Adults (Adult Treatment Panel III). USA: NIH Publication; 2001.

20. Mendall MA, Patel P, Ballam L, Strachan D, Northfield TC. C reactive protein and its relation to cardiovascular risk factors: a population based cross sectional study. BMJ.1996;312(7038):1061-5.

21. Celermajer DS, Sorensen KE, Spiegelhalter DJ, Georgakopoulos D, Robinson J, Deanfield JE. Aging is associated with endothelial dysfunction in healthy men years before the age-related decline in women. J Am Coll Cardiol. 1994;24(2):471-6.

22. Grundy SM, Becker D, Clark LT, Cooper RS, Denke MA, Howard WJ, et al. The Third Report of the National Cholesterol Education Program (NCEP) Expert Panel on Detection, Evaluation, and Treatment of High Blood Cholesterol in Adults (Adult Treatment Panel III) final report. Circulation; 2002.

23. Expert Panel on Detection E, Treatment of High Blood Cholesterol in A. Executive Summary of the Third Report of the National Cholesterol Education Program (NCEP) Expert Panel on Detection, Evaluation, and Treatment of High Blood Cholesterol in Adults (Adult Treatment Panel III). JAMA: The Journal of the American Medical Association. 2001;285(19):2486-97.

24. Stampfer MJ, Sacks FM, Salvini S, Willett WC, Hennekens CH. A prospective study of cholesterol, apolipoproteins, and the risk of myocardial infarction. N Engl J Med.1991;325(6):373-81.

25. Assmann G, Schulte H, von Eckardstein A, Huang Y. High-density lipoprotein cholesterol as a predictor of coronary heart disease risk. The PROCAM experience and pathophysiological implications for reverse cholesterol transport. Atherosclerosis. 1996;124 Suppl:S11-20.

26. Kinosian B, Glick H, Preiss L, Puder KL. Cholesterol and coronary heart disease: predicting risks in men by changes in levels and ratios. J Investig Med.1995;43(5):443-50. 